\title{
Health-related quality of life and economic implications of cutaneous T-cell lymphoma
}

\author{
AR Rosenberg, MPHS ${ }^{1}$, YR Semenov, MD, MA ${ }^{1}$, C Herbosa, $^{\text {BA }}{ }^{1}$, N Mehta-Shah, $^{\text {MD }}{ }^{2}$, AC \\ Musiek, MD ${ }^{1}$ \\ ${ }^{1}$ Washington University School of Medicine, Division of Dermatology. \\ ${ }^{2}$ Washington University School of Medicine, Siteman Cancer Center.
}

\begin{abstract}
Background: Cutaneous T-cell lymphoma (CTCL) has been associated with considerable physical, psychological, and financial burden in recent literature. Despite these findings, its impact on health-related quality of life $(\mathrm{QoL})$ and economic cost have not been well-studied.
\end{abstract}

Objectives: To measure the overall QoL impact and financial burden of CTCL.

Methods: A cross-sectional survey of 67 adult CTCL patients was conducted at an academic medical center. Normative population data ( $\mathrm{N}=3310)$ was obtained from the 2002-2003 Joint Canada/United States Survey of Health (JCUSH). QoL was measured using the Ontario Health Utilities Index Mark III (HUI3) questionnaire. Economic cost was estimated using qualityadjusted life year (QALY) loss derived from HUI3 scores.

Results: Compared to the U.S. general population, CTCL patients had significantly lower unadjusted aggregate HUI3 scores $(0.68$ vs $0.87, \mathrm{p}<0.01)$. Multivariable regression analysis controlling for demographics and comorbidities showed CTCL was associated with significantly poorer performance overall $(-0.13)$ and in the domains of hearing $(-0.04)$, speech $(-0.03)$, ambulation $(-0.04)$, dexterity $(-0.02)$, emotion $(-0.07)$, and pain $(-0.07)$. These health utility decrements yielded an average lifetime loss of 1.47 QALYs per patient. Using a \$50,000/QALY willingness to pay threshold, CTCL was associated with a lifetime burden of $\$ 73,389$ per patient and a U.S. societal burden of $\$ 2.84$ billion.

Conclusions: These findings suggest CTCL has a pervasive impact on QoL, comparable to other debilitating conditions such as end-stage renal disease. Additionally, the substantial economic burden underscores the potential societal benefit of prompt diagnosis and aggressive management of CTCL.

\section{Introduction}

Cutaneous T-cell lymphoma (CTCL) is a primary cutaneous malignancy with an estimated incidence of approximately 6.4 cases per million persons in the United States. ${ }^{1}$ Patients

Corresponding author: Yevgeniy Semenov, MD, MA, Division of Dermatology, Washington University School of Medicine, 660 S. Euclid Ave, Campus Box 8123, St. Louis, MO 63110, Phone: 443-791-3311, Fax: 314-362-8159, yevgeniy.semenov@wustl.edu. Conflicts of interest: None declared 
diagnosed with CTCL often report physical and psychological distress related to pruritus, treatment side effects, financial burden, social consequences, and prognostic concerns. ${ }^{2-4}$ From a financial perspective, CTCL has also been associated with a higher annual incremental cost than any other skin disease, ${ }^{3,5}$ though the long-term economic burden of CTCL to patients and society at large remains to be quantified. Despite the potential for this condition to compromise various aspects of patient well-being, few studies have investigated the impact of CTCL on overall health-related quality of life (QoL). ${ }^{6}$

Previous studies have relied on survey instruments which are designed to measure QoL specifically in patients with skin disease or cancer. These disease-specific QoL instruments contain items which may be particularly relevant to the population of interest and are useful in determining risk factors for poor QoL within the population of interest. Thus, existing studies have focused on variations in QoL within the CTCL patient population, stratified by demographic and clinical characteristics. For instance, it has been suggested that predictors of poor QoL include female gender, Sézary syndrome subtype, advanced stage, and treatment with systemic steroids or interferon. ${ }^{2-4,7,8}$

In contrast, disease-specific QoL instruments are less useful in comparing overall QoL in the population of interest to that of the age- and gender-matched general population or other chronic disease states. In order to quantify, interpret, and compare the overall impact of CTCL on QoL, it is necessary to use a generic health utility instrument. Health utilities are a measure of preference for various health states. A lower health utility score means that compared to living a given amount of time in perfect health, a patient would have to be allowed to live a longer amount of time in the current state of health in order to be equally preferable. Health utility scores are easily compared between populations and can be used to calculate quality-adjusted life years (QALYs), which in turn can be used to estimate the economic cost of disease and cost-effectiveness of treatment. ${ }^{9}$ Given the unique advantages of generic health utility instruments, we designed a study utilizing the Ontario Health Utilities Index Mark III (HUI3) instrument. The purpose of this study is to quantify the health utility decrement associated with CTCL in order to add to existing knowledge about the QoL impact of the disease and to calculate the lifetime financial burden for individual CTCL patients and the United States healthcare system.

\section{Materials and Methods}

\section{Recruitment and Data Collection}

Approval for this study was obtained from the Institutional Review Board at Washington University in St. Louis. Eligible participants were English-speaking adults who presented to the dedicated CTCL clinic between July 6, 2017 and November 28, 2017.

Participants were asked to complete a paper-based version of the Health Utilities Index Mark 3 (HUI3) questionnaire. The HUI3 is a 15 -item, population-based, validated health utility instrument that measures the respondent's general health status and quality of life along 8 specific domains of function: vision, hearing, speech, ambulation, dexterity, emotion, cognition, and pain. ${ }^{10}$ It has been widely used in quality of life and economic analyses of numerous cancers and chronic diseases. ${ }^{11-16}$ Each participant's individual domain and 
overall health utility scores were calculated according to the published methods for HUI3 data analysis. HUI3 scores range from 1 ("perfect health") to 0 ("death") on the individual domains and 1 ("perfect health") to - 0.36 (a state "worse than death") on the overall index. ${ }^{10}$ The unit for health utility is the quality-adjusted life year (QALY).

Normative data from the general US population was collected from the 2002-2003 Joint Canada/United States Survey of Health (JCUSH), a cross-sectional random-digit-dialed telephone survey which includes the HUI3. ${ }^{17}$ Of the 8,145 individuals who participated in JCUSH, 5,859 lived in the U.S. Among these participants, we excluded those who were less than 21 years of age, did not complete the HUI3, or were missing data on history of stroke, depression, cardiovascular disease, hypertension, arthritis, or smoking. The remaining general population sample size was 3,310.

Patient demographics, CTCL stage, and medical comorbidity data were collected from each patient's clinical records. In the normative population, history of smoking was defined in JCUSH as smoking greater than 100 cigarettes in one's lifetime. ${ }^{18}$ Hypertension was determined in JCUSH based on the question "Have you ever been told by a doctor or other health professional that you have high blood pressure, also called hypertension?"

Cardiovascular disease was assessed by the question "Have you ever been told by a doctor or other health professional that you have heart disease?" History of stroke was determined in JCUSH based the question "What condition or health problem causes you to have difficulty?" with the patient's answer as "Stroke problem." Depression was evaluated based on the question "during the past 12 months, was there ever a time when you felt sad, blue, or depressed for 2 weeks or more in a row?" Arthritis was defined based on the question "have you ever been told by a doctor or other health professional that you have arthritis, not including fibromyalgia?"18

\section{Statistical analysis}

Baseline demographic and medical history factors (Table 1) were characterized by mean and standard error for continuous variables and by frequency distributions and percentage of total for categorical variables. Baseline differences in health utilities were explored using a multivariable generalized linear model, allowing for response variables that have both Gaussian and non-Gaussian distributions. Covariates included demographic (age, gender, race, marital status) and clinical characteristics (history of smoking, hypertension, cardiovascular disease, stroke, depression, arthritis). STATA 13 (Stata Corp, College Station, TX) was used for all statistical analyses.

\section{Economic Analysis}

Total individual QALYs lost due to CTCL were calculated and averaged across all study patients by compounding the yearly adjusted health utility loss associated with CTCL across an individual's remaining life expectancy stratified by disease stage. ${ }^{19}$ A discount rate of $3 \%$ was utilized in all base QALY estimates based on the government's borrowing rate. ${ }^{20}$ The discount rate is the factor by which individuals preferentially value costs and benefits incurred in the present to those incurred in the future. A $3 \%$ discount rate implies that the 
magnitude of the QALY loss associated with CTCL will decrease each year by a factor of $1 / 1.03$ of the prior year's value.

A societal perspective analysis was performed to calculate the overall economic burden of CTCL using a widely accepted $\$ 50,000$ willingness to pay (WTP) threshold to gain one QALY. ${ }^{21}$ The economic burden associated with QALY loss in our CTCL patient sample was then generalized to the overall susceptible U.S. adult population using estimated CTCL prevalence and U.S. census data. CTCL prevalence was calculated based on the literaturederived incidence of 6.4 cases per 1,000,000 persons and a stage-weighted average years to life expectancy of 18.7 years. ${ }^{1,19}$

Base case results were calculated for each age group using a $3 \%$ discount rate, a $\$ 50,000$ WTP threshold, a weighted CTCL prevalence of 120 per 1,000,000 persons, and an annual health utility decrease of 0.12 , equivalent to the CTCL coefficient derived from the adjusted generalized linear model of overall HUI3 score. Sensitivity analyses were performed by varying these four parameters.

\section{Results}

Among 80 consecutive CTCL patients, 3 were not recruited due to mental status or language barrier preventing completion of the study questionnaire. Of the 77 eligible patients, 5 declined participation. Five of the 72 patients who consented did not ultimately complete the questionnaire. Thus, the final study sample consisted of the 67 patients. Baseline demographic characteristics and comorbidity status of the study population and general population $(n=3,310)$ are presented in Table 1 . Among the CTCL patients, $47.8 \%$ were female and $80.6 \%$ were non-Hispanic white. Ages ranged from 24 to 90 years, with a mean age of 65 (SD 12.8) years, and the mean time elapsed since definitive diagnosis of CTCL was 7 months (SD 15). Compared to the CTCL patient population at large, the age distribution was similar, although females were overrepresented in the study sample. ${ }^{22}$

Mean overall HUI3 scores were compared between CTCL patients and the general population as shown in Table 1 . The mean overall HUI3 score in the study population was significantly lower than that of the general population ( 0.68 vs. 0.87 , respectively; $\mathrm{p}<0.01$ ). Overall HUI3 scores were generally lower in the CTCL population across age, gender, race, income, and marital status strata. Mean scores in each functional domain were also reduced in the CTCL patients, as shown in Table 2. Compared to the general population, the study population exhibited significant health utility reductions in the domains of hearing ( 0.93 vs. 0.98 , respectively), speech ( 0.97 vs. 1.0 , respectively), ambulation ( 0.89 vs. 0.97 , respectively), dexterity ( 0.96 vs. 0.99 , respectively), emotion ( 0.90 vs. 0.97 , respectively), and pain ( 0.83 vs. 0.93 , respectively).

A multivariable linear regression model illustrating the association between overall HUI3 score, CTCL, and demographic and medical history variables is presented in Table 3. All models were adjusted for age, gender, race, income category, marital status, current or past smoking status, and history of hypertension, cardiovascular disease (including angina, coronary artery disease, myocardial infarction, or congestive heart failure), stroke, 
depression, and, arthritis. CTCL was associated with a significant reduction in overall HUI3 score by 0.13 points compared to the general population ( $95 \%$ CI -0.18 to $-0.09, \mathrm{p}<0.01$ ). Other factors associated with a significant decrease in overall health utility included increasing age $(-0.01, \mathrm{p}=0.03)$, estimated income less than $\$ 40,000(-0.04, \mathrm{p}<0.01)$, widowed marital status (compared to single reference group; $-0.05,95 \% \mathrm{CI}-0.08$ to -0.02 , $\mathrm{p}<0.01)$, hypertension $(-0.02, \mathrm{p}<0.01)$, stroke $(-0.34,95 \%$ CI -0.41 to $-0.26, \mathrm{p}<0.01)$, depression, $(-0.19,95 \% \mathrm{CI}-0.21$ to $-0.17, \mathrm{p}<0.01)$, cardiovascular disease $(-0.10,95 \% \mathrm{CI}$ -0.12 to $-0.07, \mathrm{p}<0.001)$, arthritis $(-0.12,95 \% \mathrm{CI}-0.014$ to $-0.10, \mathrm{p}<0.01)$, and smoking $(-0.02,95 \%$ CI -0.03 to $-0.01, \mathrm{p}<0.01)$.

Similar multivariable linear regression models were performed to assess the association between CTCL and individual HUI3 domains is shown in Table 4. CTCL was associated with a significant decline in all functional domains except for vision and cognition. The affected domains included hearing $(-0.04,95 \% \mathrm{CI}-0.07$ to $-0.02, \mathrm{p}<0.01)$, speech $(-0.03$, $95 \% \mathrm{CI}-0.04$ to $-0.03, \mathrm{p}<0.01)$, ambulation $(-0.03,95 \% \mathrm{CI}-0.06$ to $0.00, \mathrm{p}=0.03)$, dexterity $(-0.02,95 \% \mathrm{CI}-0.04$ to $0.00, \mathrm{p}=0.02)$, emotion $(-0.06,95 \%-0.08$ to -0.03 , $\mathrm{p}<0.01)$, and pain $(-0.05,95 \% \mathrm{CI}-0.11$ to $0.00, \mathrm{p}=0.04)$.

The health utility decline associated with CTCL was used to calculate the economic burden of the disease in the U.S. The steps required to perform this calculation are represented in Table 5. A CTCL prevalence of 120 cases per million persons was calculated by multiplying an incidence of 6.4 cases per million persons by the stage-weighted average survival times. ${ }^{1,19}$ Applying U.S. Census data, 38,765 persons were estimated to be living with CTCL. ${ }^{23}$ Given an annual health utility loss of 0.13 at a discount rate of $3 \%$ across the years to life expectancy, CTCL was found to be responsible for an average loss of 1.47 QALYs per patient, or 56,899 QALYs for the entire U.S. CTCL patient population. Using a highly conservative WTP threshold of $\$ 50,000$ per QALY, this corresponds to an individual CTCL patient burden of $\$ 73,389$ and a societal burden of $\$ 2.84$ billion. ${ }^{21}$ Sensitivity analyses were performed for discount rate range of 0-6\%, annual HUI loss of 0.08-0.18, CTCL prevalence of 60 to 180 cases per million persons, and WTP threshold of $\$ 25,000-\$ 75,000$ per QALY. The widest economic burden ranges found by these analyses were $\$ 36,695-\$ 110,084$ individually and $\$ 1.42-\$ 4.27$ billion societally, sensitive to changes in WTP threshold.

\section{Discussion}

The results suggest that CTCL in adults is strongly associated with poor QoL outcomes. The mean overall HUI3 score in our CTCL patient population was 0.68 , which corresponds to severe disability. ${ }^{24}$ This is greater than the level of QoL impairment associated with hemodialysis (0.73), ${ }^{14}$ diabetes mellitus (0.78), ${ }^{16}$ and the all-cancer patient population (0.78) ${ }^{16}$ In contrast, it is not as large as the QoL decline associated with osteoarthritis $(0.46),{ }^{12}$ stroke (0.60), ${ }^{15}$ or heart failure with an implantable cardioverter defibrillator (0.64). ${ }^{13}$ Further, CTCL was found to have an independent influence on QoL after adjusting for age, gender, race, income, marital status, and history of hypertension, stroke, depression, and arthritis. In fact, CTCL was associated with the third largest QoL decrement of all variables considered, behind only stroke and depression. 
As anticipated, CTCL was associated with a large health utility decrement in the emotional domain. Previous studies have shown that CTCL is associated with decreased psychological well-being, especially in patients with advanced-stage disease. ${ }^{3,8}$ CTCL patients frequently report embarrassment, frustration, depression, anxiety, and fear of death. ${ }^{3}$ Selfconsciousness about rash appearance or scratching behavior may lead to social withdrawal and impaired sexual activity. Social support has been shown to be an important factor in the emotional well-being of patients with cancer ${ }^{25}$ or chronic skin diseases, ${ }^{26}$ and CTCL patients who are reluctant to be around other people may be particularly susceptible to poor coping.

The results also confirmed our expectation that CTCL patients would experience a substantial reduction in health utility in the pain domain. The majority of patients with CTCL experience pruritus, which is often severe and distressing enough to be perceived as pain. ${ }^{2,27-29}$ Because there are no HUI3 items that specifically address pruritus, it is likely that this common symptom is reflected by the pain domain score. Treatments aimed at controlling CTCL have had variable success in reducing itching, ${ }^{29-31}$ and patients may report symptomatic pruritus even when the skin appears to be clear. ${ }^{31}$ Thus, refractory pruritus can be not only physically uncomfortable but psychologically upsetting. Pruritus has similarly been associated with reduced QoL in patients with psoriasis and atopic dermatitis, and in the atopic dermatitis population, it has been independently associated with psychological distress. ${ }^{26}$ These results highlight the importance of finding effective treatments specifically for pruritus in order to maximize QoL in the CTCL patient population.

Additionally, we found a significant decline in ambulation and dexterity among CTCL patients. These effects likely vary based on the body areas involved, though we did not have a large enough sample size to conduct sub-analyses by anatomical location. Patients with lower extremity disease may experience difficulty ambulating, and involvement of the soles of the feet may even result in some patients becoming wheelchair-bound. Similarly, dexterity may be particularly reduced in cases of hand involvement. Ambulation and dexterity could also be compromised in cases of peripheral neuropathy, which has been associated with certain chemotherapeutic agents including brentuximab, ${ }^{32}$ and rarely with the disease itself. ${ }^{33}$ Finally, health utility in the domains of hearing and speech were found to be significantly reduced in association with CTCL. The mechanism for these findings is unclear.

Though not specifically addressed by the HUI3 questionnaire, financial stress is another commonly reported concern among CTCL patients. ${ }^{3}$ In cancer survivors, financial hardship related to cancer treatment has been strongly associated with poor QoL outcomes in physical, emotional, and social domains. ${ }^{34}$ CTCL patients may incur substantial direct and indirect expenses of treatment, such as transportation to medical appointments and light therapy sessions, and they may be forced to take time off from work as a result of their therapeutic regimen or severe symptoms. The individual annual cost of CTCL has been previously estimated as $\$ 3,948 .^{5}$ In this context, our estimate of $\$ 73,389$ over the lifetime of an individual patient would have to correspond to an average life expectancy of 18.6 years after CTCL diagnosis. In fact, the stage-weighted CTCL-specific life expectancy in our patient population was 18.7 years. ${ }^{19}$ Thus, our individual lifetime economic burden estimate 
is fairly consistent with this recent annual estimate. Despite its relatively low prevalence, CTCL is also associated with a sizable lifetime financial burden to the U.S. overall (\$2.84 billion), suggesting that improvements in CTCL management have the potential to result in considerable societal benefit.

The generalizability of this study is limited by its single-institutional design. Relatively small sample size precluded sub-analyses by clinical characteristics such as stage and treatment regimen, which have previously been shown to be significant predictors of QoL. 3,8 Based on the most advanced stage documented since time of diagnosis, there were 45 patients with early disease (stage IA-IIA) and 22 patients with advanced disease (stage IIBIVB). Despite the low absolute number of patients with advanced CTCL, these patients constituted $31.3 \%$ of our study sample, which is similar to the early- versus advanced-stage distribution in the overall CTCL patient population. ${ }^{19}$ Further, the cross-sectional nature of this study did not allow us to trend QoL with treatment over time. Finally, the HUI3 is a generic health utility instrument which is not designed to evaluate aspects of QoL that may be of particular significance in the CTCL population. Unlike many other types of cancer and chronic skin diseases, there is currently no validated CTCL-specific QoL questionnaire. ${ }^{35-37}$ The advantage of our decision to use the HUI3, rather than a cancer- or skin-directed questionnaire, is that it facilitates comparison of health utility in the CTCL patient population to that of other populations, and allows for calculation of economic burden.

\section{Conclusions}

The CTCL patient population has significantly reduced overall health-related QoL compared to the general U.S. population. The largest CTCL-associated QoL reductions are seen in the domains of emotion and pain. Additionally, significant deficits are apparent in the domains of hearing, speech, ambulation, and dexterity. These findings suggest that CTCL is associated with a profound decline in $\mathrm{QoL}$ and individual financial burden akin to other debilitating chronic diseases. Further, the total U.S. economic burden of CTCL demonstrates the potential societal benefits of prompt diagnosis and effective management of this condition.

\section{References}

1. Criscione VD, Weinstock MA. Incidence of cutaneous T-cell lymphoma in the United States, 19732002. Arch Dermatol. 2007;143(7):854-859. [PubMed: 17638728]

2. Wright A, Wijeratne A, Hung T, et al. Prevalence and severity of pruritus and quality of life in patients with cutaneous T-cell lymphoma. J Pain Symptom Manage. 2013;45(1):114-119. [PubMed: 22917715]

3. Demierre MF, Gan S, Jones J, Miller DR. Significant impact of cutaneous T-cell lymphoma on patients' quality of life: Results of a 2005 National Cutaneous Lymphoma Foundation Survey. Cancer. 2006;107(10):2504-2511. [PubMed: 17048251]

4. Demierre M-F, Olsen EA, Williams CA, Arduino JM, McNaughton KS. An In-Depth Assessment of the Impact of Pruritus on Health-Related Quality of Life of Patients with Mycosis Fungoides/Sézary Syndrome. J Support Oncol. 2011;9(3):e13-e19.

5. Lim HW, Collins SAB, Resneck JS Jr., et al. A risk adjustment approach to estimating the burden of skin disease in the United States. J Am Acad Dermatol. 2018;78(1):129-140. [PubMed: 29110889]

6. Dalal M, Mitchell S, McCloskey C, Zagadailov E, Gautam A. Epidemiological and humanistic burden of cutaneous T-cell lymphomas: results of a systemic review. 2016;(December):389-390. 
7. Demierre M-F, Tien A, Miller D. Health-related quality-of-life assessment in patients with cutaneous T-cell lymphoma. Arch Dermatol. 2005;141(3):325-330. [PubMed: 15781673]

8. Sampogna F, Frontani M, Baliva G, et al. Quality of life and psychological distress in patients with cutaneous lymphoma. Br J Dermatol. 2009;160(4):815-822. [PubMed: 19120325]

9. Askew RL, Swartz RJ, Xing Y, et al. Mapping FACT-melanoma quality-of-life scores to EQ-5D health utility weights. Value Heal. 2011.

10. Horsman J, Furlong W, Feeny D, Torrance G. The Health Utilities Index (HUI®): Concepts, measurement properties and applications. Health Qual Life Outcomes. 2003;1:1-13. [PubMed: 12605709]

11. Semenov YR, Yeh ST, Seshamani M, et al. Age dependent cost-utility of pediatric cochlear implantation. Ear Hear. 2013;34(4):402-412. [PubMed: 23558665]

12. Ruchlin HS, Insinga RP. A review of health-utility data for osteoarthritis: Implications for clinical trial-based evaluation. Pharmacoeconomics. 2008;26(11):925-935. [PubMed: 18850762]

13. Noyes K, Corona E, Veazie P, Dick AW, Zhao H, Moss AJ. Examination of the Effect of Implantable Cardioverter- Defibrillators on Health-Related Quality of Life: Based on Results from the Multicenter Automatic Defibrillator Trial-II. Am J Cardiovasc Drugs. 2009;9(6):393-400. [PubMed: 19929037]

14. Heidenheim AP, Muirhead N, Moist L, Lindsay RM. Patient quality of life on quotidian hemodialysis. Am J Kidney Dis. 2003;42(1):36-41.

15. Edwards JD, Koehoorn M, Boyd LA, Levy AR. Is health-related quality of life improving after stroke?: A comparison of health utilities indices among canadians with stroke between 1996 and 2005. Stroke. 2010;41(5):996-1000. [PubMed: 20360545]

16. Bowker SL, Pohar SL, Johnson JA. A cross-sectional study of health-related quality of life deficits in individuals with comorbid diabetes and cancer. Health Qual Life Outcomes. 2006;4:1-9. [PubMed: 16393335]

17. Sanmartin C, Berthelot J-M, Ng E, et al. Comparing Health And Health Care Use In Canada And The United States. Health Aff. 2006;25(4):1133-1142.

18. Sanmartin C, Ng E, Blackwell D, Gentleman J, Martinez M, Simile C. Joint Canada-United States Survey of Health Questionnaire Final. 2004:1-60. http://www.cdc.gov/nchs/data/nhis/ jcush_analyticalreport.pdf.

19. Agar NS, Wedgeworth E, Crichton S, et al. Survival outcomes and prognostic factors in mycosis fungoides/Sézary syndrome: Validation of the revised International Society for Cutaneous Lymphomas/European Organisation for Research and Treatment of Cancer staging proposal. J Clin Oncol. 2010;28(31):4730-4739. [PubMed: 20855822]

20. Lind RC. Reassessing the government's discount rate policy in light of new theory and data in a world economy with a high degree of capital mobility. J Environ Econ Manage. 1995;18(2, Part 2): $8-28$.

21. Hirth RA, Chernew ME, Miller E, Fendrick AM, Weissert WG. Willingness to Pay for a Qualityadjusted Life Year: In Search of a Standard. Med Decis Mak. 2000;20(3):332-342.

22. Bradford PT, Devesa SS, Anderson WF, Toro JR. Cutaneous lymphoma incidence patterns in the United States: a population-based study of 3884 cases. Blood. 2009;113(21):5064-5073. [PubMed: 19279331]

23. Table 1. Annual Estimates of the Resident Population for the United States, Regions, States, and Puerto Rico: April 1, 2010 to July 1, 2017 (NST-EST2017-01). 2017 https://www.census.gov/data/ datasets/2017/demo/popest/nation-total.html.

24. Feng Y, Bernier J, McIntosh C, Orpana H. Validation of disability categories derived from Health Utilities Index Mark 3 scores. Heal reports. 2009;20(2):43-50.

25. Kim J, Han Jeong Yeob, Shaw B, McTavish F, Gustafson D. The Roles of Social Support and Coping Strategies in Predicting Breast Cancer Patients' Emotional Well-being. J Health Psychol. 2010;15(4):543-552. [PubMed: 20460411]

26. Evers AWM, Lu Y, Duller P, Van Der Valk PGM, Kraaimaat FW, Van De Kerkhoft PCM. Common burden of chronic skin diseases? Contributors to psychological distress in adults with psoriasis and atopic dermatitis. Br J Dermatol. 2005;152(6):1275-1281. [PubMed: 15948993] 
27. Meyer N, Paul C, Misery L. Pruritus in cutaneous T-cell lymphomas: Frequent, often severe and difficult to treat. Acta Derm Venereol. 2010;90(1):12-17. doi:10.2340/00015555-0789 [PubMed: 20107719]

28. Ahem K, Gilmore E, Poligone B. Pruritus in Cutaneous T-cell Lymphoma: A Review. J Am Acad Dermatol. 2012;67(4):760-768. [PubMed: 22285672]

29. Field H, Gao L, Motwani P, Wong HK. Pruritus Reduction with Systemic Anti-lymphoma Treatments in Patients with Cutaneous T Cell Lymphoma: A Narrative Review. Dermatol Ther (Heidelb). 2016;6(4):579-595. [PubMed: 27590615]

30. Olsen EA, Kim YH, Kuzel TM, et al. Phase IIB multicenter trial of vorinostat in patients with persistent, progressive, or treatment refractory cutaneous t-cell lymphoma. J Clin Oncol. 2007;25(21):3109-3115. [PubMed: 17577020]

31. Kim YH, Demierre M-F, Kim EJ, et al. Clinically meaningful reduction in pruritus in patients with cutaneous T-cell lymphoma treated with romidepsin. Leuk Lymphoma. 2013;54(2):284-289. [PubMed: 22839723]

32. Prince HM, Kim YH, Horwitz S, et al. Brentuximab vedotin or physician's choice in CD30positive cutaneous T-cell lymphoma (ALCANZA): an international, open-label, randomised, phase 3, multicentre trial. Lancet. 2017;390(10094):555-566. doi:10.1016/S0140-6736(17)31266-7 [PubMed: 28600132]

33. Karadağ YS, Gülünay A, Öztekin N, Ak F, Kilıçkap S. Peripheral Neuropathy in Sézary Syndrome: Coincidence or a Part of the Syndrome? Turkish J Hematol. 2013;30(4):420-421.

34. Fenn KM, Evans SB, McCorkle R, et al. Impact of Financial Burden of Cancer on Survivors' Quality of Life. J Oncol Pract. 2014;10(5):332-338. doi:10.1200/JOP.2013.001322 [PubMed: 24865220]

35. Wicks P, Sepassi M, Sharma G, Carlson Delogne M. Partnering With Patients to Rapidly Develop a Quality-of-Life Measure in Mycosis Fungoides/Sézary Syndrome Type Cutaneous T-cell Lymphoma. Am J Manag Care. 2016;22(8).

36. Chren M-M, Lasek RJ, Quinn LM, Mostow EN, Zyzanski SJ. Skindex, a Quality-of-Life Measure for Patients with Skin Disease: Reliability, Validity, and Responsiveness. J Invest Dermatol. 1996;107(5):707-713. [PubMed: 8875954]

37. Cormier JN, Davidson L, Xing Y, Webster K, Cella D. Measuring quality of life in patients with melanoma: development of the FACT-melanoma subscale. J Support Oncol. 3(2):139-145. http:// www.ncbi.nlm.nih.gov/pubmed/15796446. Accessed November 27, 2017. 


\section{What's known/what's new:}

- $\quad$ Cutaneous T-cell lymphoma is associated with physical, psychological, and financial burden.

- The overall quality of life impact of cutaneous T-cell lymphoma has not previously been measured using a generic health utility instrument.

- In this study, we compare the overall quality of life burden of cutaneous T-cell lymphoma to that of other populations and calculate the economic burden of the disease. 
Table 1.

Quality of life attainment in patients with CTCL by demographic and medical history factors.

\begin{tabular}{|c|c|c|c|c|}
\hline \multicolumn{3}{|c|}{ CTCL (n=67) } & \multicolumn{2}{|c|}{ General Population $(\mathrm{n}=\mathbf{3 3 1 0})$} \\
\hline Characteristic & $\mathbf{N}(\%)$ & HUI3 Mean (SE) & $\mathbf{N}(\%)$ & HUI3 Mean (SE) \\
\hline \multicolumn{5}{|l|}{ Gender } \\
\hline Male & $35(52.2)$ & $0.71(0.26)$ & 1476 (44.6) & $0.88(0.20)$ \\
\hline Female & $32(47.8)$ & $0.65(0.33)$ & $1834(55.4)$ & $0.85(0.23)$ \\
\hline \multicolumn{5}{|l|}{ Age } \\
\hline $21-29$ years & $1(1.5)$ & $0.67(0.00)$ & $442(13.4)$ & $0.91(0.17)$ \\
\hline $30-39$ years & $1(1.5)$ & $0.92(0.00)$ & $728(22.0)$ & $0.91(0.16)$ \\
\hline $40-49$ years & $6(9.0)$ & $0.72(0.26)$ & $778(23.5)$ & $0.88(0.19)$ \\
\hline $50-59$ years & $12(17.9)$ & $0.63(0.42)$ & $601(18.2)$ & $0.84(0.23)$ \\
\hline $60-69$ years & $24(35.8)$ & $0.75(0.22)$ & $389(11.8)$ & $0.83(0.24)$ \\
\hline $70-79$ years & $16(23.9)$ & $0.68(0.29)$ & $266(8.0)$ & $0.78(0.26)$ \\
\hline$>=80$ years & $7(10.4)$ & $0.48(0.29)$ & $106(3.2)$ & $0.70(0.31)$ \\
\hline \multicolumn{5}{|l|}{ Race } \\
\hline Non-Hispanic White & $54(80.6)$ & $0.72(0.27)$ & $2517(76.0)$ & $0.87(0.21)$ \\
\hline Non-Hispanic Black & $12(17.9)$ & $0.50(0.35)$ & $242(7.3)$ & $0.82(0.27)$ \\
\hline Hispanic & $1(1.5)$ & $0.97(0.00)$ & $332(10.0)$ & $0.85(0.22)$ \\
\hline Asian & NA & NA & $94(2.8)$ & $0.91(0.15)$ \\
\hline Other & NA & NA & $125(3.8)$ & $0.85(0.22)$ \\
\hline \multicolumn{5}{|c|}{ Annual Household income } \\
\hline$<\$ 40,000$ & $11(16.4)$ & $0.51(0.37)$ & $1336(40.4)$ & $0.80(0.26)$ \\
\hline$\$ 40,000-\$ 80,000$ & $47(70.1)$ & $0.72(0.26)$ & $1213(36.6)$ & $0.90(0.17)$ \\
\hline$>=\$ 80,000$ & $9(13.4)$ & $0.66(0.32)$ & $761(23.0)$ & $0.93(0.13)$ \\
\hline \multicolumn{5}{|l|}{ Marital Status } \\
\hline Single & $11(16.4)$ & $0.69(0.34)$ & $543(16.4)$ & $0.88(0.19)$ \\
\hline Married & 48 (71.6) & $0.71(0.27)$ & $1955(59.1)$ & $0.89(0.19)$ \\
\hline Widowed & $7(10.4)$ & $0.53(0.40)$ & $267(8.1)$ & $0.73(0.30)$ \\
\hline Divorced & $1(2.5)$ & $0.45(0.00)$ & $542(16.4)$ & $0.83(0.24)$ \\
\hline \multicolumn{5}{|l|}{ Smoking } \\
\hline Yes & $9(13.4)$ & $0.78(0.22)$ & $1601(48.4)$ & $0.84(0.23)$ \\
\hline No & $58(86.6)$ & $0.67(0.30)$ & 1709 (51.6) & $0.89(0.18)$ \\
\hline \multicolumn{5}{|l|}{ Hypertension } \\
\hline Yes & $40(59.7)$ & $0.62(0.30)$ & $814(24.6)$ & $0.79(0.28)$ \\
\hline No & $27(40.3)$ & $0.77(0.27)$ & $2496(75.4)$ & $0.89(0.18)$ \\
\hline \multicolumn{5}{|l|}{ Cardiovascular disease } \\
\hline Yes & $15(22.4)$ & $0.66(0.24)$ & $219(6.6)$ & $0.66(0.32)$ \\
\hline No & $52(77.6)$ & $0.69(0.31)$ & $3090(93.4)$ & $0.88(0.19)$ \\
\hline \multicolumn{5}{|l|}{ Stroke } \\
\hline Yes & $5(7.5)$ & $0.55(0.11)$ & $18(0.5)$ & $0.30(0.26)$ \\
\hline No & $62(92.5)$ & $0.69(0.30)$ & $3292(99.5)$ & $0.87(0.21)$ \\
\hline
\end{tabular}




\begin{tabular}{lcccc}
\hline & CTCL $(\mathbf{n = 6 7 )}$ & & \multicolumn{2}{c}{ General Population $(\mathbf{n = 3 3 1 0})$} \\
\hline Characteristic & $\mathbf{N}(\%)$ & HUI3 Mean $($ SE) & N $(\%)$ & HUI3 Mean $($ SE) \\
\hline Depression/Anxiety & & & & \\
$\quad$ Yes & $7(10.4)$ & $0.65(0.32)$ & $379(11.5)$ & $0.66(0.32)$ \\
No & $60(89.6)$ & $0.68(0.29)$ & $2931(88.5)$ & $0.89(0.18)$ \\
\hline Arthritis & & & \\
Yes & $22(32.8)$ & $0.63(0.25)$ & $687(20.8)$ & $0.71(0.29)$ \\
No & $45(67.2)$ & $0.70(0.31)$ & $2623(79.2)$ & $0.90(0.16)$ \\
\hline
\end{tabular}

Abbreviations: HUI3, Health Utilities Index Mark III; SE, Standard Error; NA, Not Applicable. 
Table 2.

Mean unadjusted HUI3 domain and overall scores for participants with CTCL and the general population.

\begin{tabular}{llllllllll}
\hline Domain & Vision & Hearing $^{\boldsymbol{a}}$ & Speech $^{\boldsymbol{a}}$ & Ambulation $^{\boldsymbol{a}}$ & Dexterity $^{\boldsymbol{a}}$ & Emotion $^{\boldsymbol{a}}$ & Cognition Pain $^{\boldsymbol{a}}$ & Overall $^{\boldsymbol{a}}$ \\
\hline Patients & 0.96 & 0.93 & 0.97 & 0.89 & 0.96 & 0.90 & 0.93 & 0.83 & 0.68 \\
\hline Controls & 0.96 & 0.98 & 1.00 & 0.97 & 0.99 & 0.97 & 0.95 & 0.93 & 0.87 \\
\hline
\end{tabular}

${ }^{a}$ Denotes p-value $<0.05$ 
Table 3.

Multivariable adjusted generalized linear model on the association of overall HUI3 score with CTCL.

\begin{tabular}{|c|c|c|c|}
\hline \multirow[b]{2}{*}{ Variable } & \multicolumn{3}{|c|}{ Health Utilities Index Mark III Overall Score } \\
\hline & Coefficient & 95\% Confidence Interval & p-value \\
\hline CTCL & -0.13 & $-0.18,-0.09$ & $<0.01$ \\
\hline Female & 0.00 & $-0.01,0.02$ & 0.64 \\
\hline Age & -0.01 & $-0.01,0.00$ & 0.03 \\
\hline \multicolumn{4}{|l|}{ Race } \\
\hline Non-Hispanic White & $\operatorname{ref}^{t^{t}}$ & $\mathrm{ref}^{t}$ & $\mathrm{ref}^{t^{t}}$ \\
\hline Non-Hispanic Black & -0.03 & $-0.05,0.01$ & 0.02 \\
\hline Hispanic & -0.02 & $-0.04,0.00$ & 0.12 \\
\hline Asian & -0.02 & $-0.05,0.02$ & 0.40 \\
\hline Other & 0.01 & $-0.03,0.04$ & 0.76 \\
\hline \multicolumn{4}{|l|}{ Income } \\
\hline$<\$ 40,000$ & $\operatorname{ref}^{f}$ & $\mathrm{ref}^{t}$ & $\mathrm{ref}^{t^{t}}$ \\
\hline$\$ 40,000-\$ 80,000$ & 0.04 & $0.03,0.06$ & $<0.01$ \\
\hline$>=\$ 80,000$ & 0.06 & $0.05,0.08$ & $<0.01$ \\
\hline \multicolumn{4}{|l|}{ Marital Status } \\
\hline Single & $\operatorname{ref}^{t}$ & $\mathrm{ref}^{t}$ & $\mathrm{ref}^{t^{t}}$ \\
\hline Married & 0.00 & $-0.02,0.02$ & 0.87 \\
\hline Widowed & -0.05 & $-0.08,-0.02$ & $<0.01$ \\
\hline Divorced & -0.01 & $-0.03,0.02$ & 0.65 \\
\hline Hypertension & -0.02 & $-0.04,0.01$ & $<0.01$ \\
\hline Smoking & -0.02 & $-0.03,-0.01$ & $<0.01$ \\
\hline Cardiovascular disease & -0.10 & $-0.12,-0.07$ & $<0.01$ \\
\hline Stroke & -0.34 & $-0.41,-0.26$ & $<0.01$ \\
\hline Depression & -0.19 & $-0.21,-0.17$ & $<0.01$ \\
\hline Arthritis & -0.12 & $-0.14,-0.10$ & $<0.01$ \\
\hline
\end{tabular}


Table 4.

Multivariable adjusted generalized linear models on the association of CTCL with individual HUI3 domains

\begin{tabular}{lccc}
\hline Outcome Variable $^{\boldsymbol{a}}$ & Coefficient & $\mathbf{9 5 \%}$ Confidence Interval & p-value \\
\hline Vision & 0.01 & $-0.01,0.02$ & 0.48 \\
\hline Hearing & -0.04 & $-0.06,-0.01$ & $<0.01$ \\
\hline Speech & -0.03 & $-0.04,-0.02$ & $<0.01$ \\
\hline Ambulation & -0.04 & $-0.07,-0.02$ & $<0.01$ \\
\hline Dexterity & -0.02 & $-0.04,-0.01$ & $<0.01$ \\
\hline Emotion & -0.07 & $-0.09,-0.05$ & $<0.01$ \\
\hline Cognition & -0.01 & $-0.04,0.02$ & 0.47 \\
\hline Pain & -0.07 & $-0.12,-0.02$ & $<0.01$ \\
\hline
\end{tabular}

Abbreviations: HUI3, Health Utilities Index Mark III.

${ }^{a}$ All models adjusted for age, gender, race, income category, marital status, smoking status, and history of hypertension, cardiovascular disease, stroke, depression, and arthritis. 
Table 5.

Economic burden of CTCL and sensitivity analyses

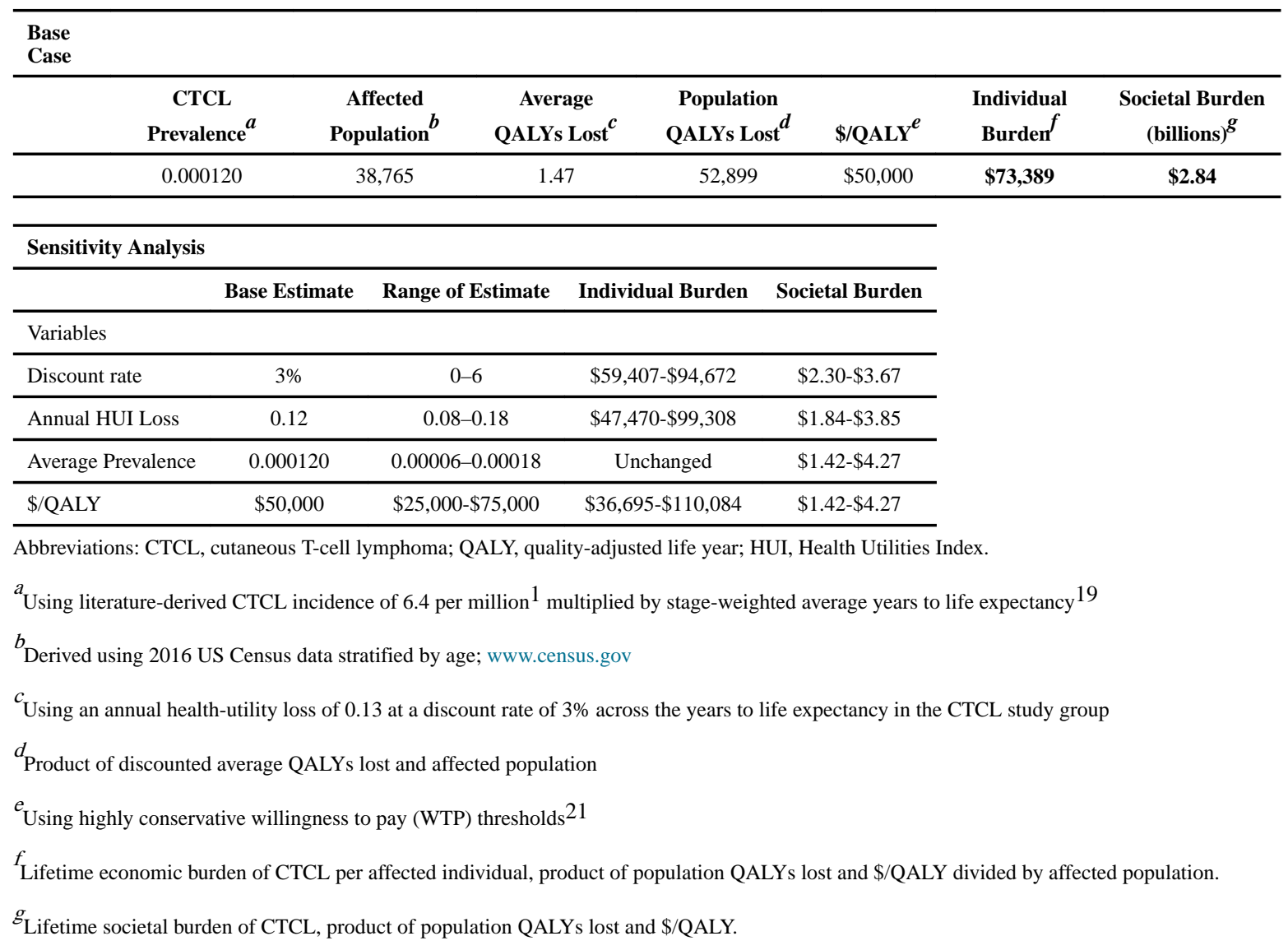

